\title{
AUXILIARES NA EDUCAÇÃO INFANTIL: ENTRE CUIDAR E EDUCAR
}

\section{ARTIGO ORIGINAL}

SOUZA, Emily Bomfim ${ }^{1}$

SOUZA, Emily Bomfim. Auxiliares na Educação Infantil: Entre cuidar e educar. Revista Científica Multidisciplinar Núcleo do Conhecimento. Ano 05, Ed. 12, Vol. 06, pp. 152-163. Dezembro de 2020. ISSN: 2448-0959, Link de acesso: https://www.nucleodoconhecimento.com.br/educacao/auxiliares-naeducacao

\section{RESUMO}

Este artigo tem por objetivo compreender a luta das Auxiliares de Desenvolvimento da educação Básica pelo reconhecimento docente no município de [2] Carapicuíba. Diante disto, questiona-se: As Auxiliares possuem a formação mínima exigida por lei, para atuarem como professoras de Educação Infantil como reivindicam? Para abarcar tal questão, foi realizada um questionário com cerca de 300 profissionais entre Auxiliares e Pajens, no intuito de verificar o nível de formação dessas profissionais. A partir das respostas aferidas ao questionário, percebeu-se um número expressivo de profissionais que tem formação completa no curso de Licenciatura plena em pedagogia e que almejam uma transformação do cargo para assumirem oficialmente o papel de professoras, superando a dissociação histórica entre cuidar e educar.

Palavras-chave: Auxiliares, docência, cuidar, educar.

\section{INTRODUÇÃO}

Desde a constituição federal de 1988 foi previsto que o profissional destinado a atuação com as crianças na Educação Infantil, seria o sujeito devidamente habilitado para ser professor, porém torna-se muito comum que sejam as chamadas auxiliares

\footnotetext{
${ }^{1}$ Graduanda em pedagogia.
} 
as responsáveis por boa parte deste papel, no entanto, sem terem o devido reconhecimento, uma vez que, suas práticas cotidianas transcendem as atribuições destinadas ao serem contratadas, como assumir sala, mas não fazem se quer parte do quadro do magistério e muito menos são reconhecidas como docentes. (PINHEIRO, 2017)

Os municípios ao considerarem contratar profissionais para atuarem diretamente com as crianças, sem a exigência mínima prevista na LDB (1996), revela implicitamente a importância que eles reportam para a profissionalização da docência e propriamente a importância que dão para a Educação Infantil. As auxiliares, pajens, crecheiras, berçaristas ou atendentes de maternais, são intrinsecamente na creche, as profissionais que mantem um contato muito direto com as crianças pequenas na busca pela garantia de um atendimento educacional de qualidade. Assim, torna-se inconcebível que essas profissionais sejam desvalorizadas e que não exista uma real reflexão dos municípios frente a regularização do cargo com as exigências previstas em lei para atuação como professoras de Educação Infantil.

Diante disso, buscasse responder com as pesquisas realizadas neste artigo a seguinte indagação: As Auxiliares possuem a formação mínima exigida por lei, para atuarem como professoras de Educação Infantil como reivindicam? Em busca de respostas a tal indagação, realizou-se um questionário com cerca de 300 auxiliares e pajens do município de Carapicuíba, no intuito de perceber o percentual de profissionais que estão de acordo com as exigências para o cargo de professor. $O$ presente artigo está organizado em fundamentação teórica, metodologia, resultados e discussões, considerações finais e referências.

\section{FUNDAMENTAÇÃO TEÓRICA}

\subsection{O BINÔMIO CUIDAR E EDUCAR}

[...] os debates em nível nacional e internacional apontam para a necessidade de que as instituições de educação infantil incorporem de maneira integrada as funções de educar e cuidar, não mais diferenciando nem hierarquizando os profissionais e instituições que 
atuam com as crianças pequenas e/ou aqueles que trabalham com as maiores. (RCNEI, 1998, v.01, p.23)

Como previsto no RCNEI cuidar e educar são funções que devem estar integradas na Educação Infantil, em prol de atender as necessidades e especificidades que essa fase da educação básica demanda. No entanto, intrinsecamente a creche, por muitos anos adotou um caráter puramente assistencialista, no qual os familiares das crianças previam que ao deixarem seus filhos na creche, seria uma garantia de que teriam os cuidados elementares, como alimentação e higiene, mas com os avanços no campo da ciência e política essa percepção sofreu alterações, como reitera Nascimento (2010, p.557),

O princípio de reconhecimento dos direitos das crianças e os avanços na produção de conhecimento marcaram a legislação subsequente assim como as políticas públicas, as quais interferiram nas pesquisas sobre crianças pequenas. As crianças começaram a ser vistas como ocupando lugar de protagonistas de suas vidas, como cidadãos em desenvolvimento, ou seja, como atores sociais, como sujeitos de direitos.

Com essas novas considerações sobre o papel social da criança, tornou-se evidente que a função da creche vai muito além do cuidado em sua concepção reducionista, diretamente interligada ao caráter assistencialista. Sabe-se que as crianças precisam ser atendidas como sujeito integral e de direitos, no qual, deve ter na creche a garantia de seu desenvolvimento pleno. Neste contexto, faz-se necessário considerar que as experiências que ocorrem no chão da escola devem estar atreladas ao cuidar e educar indissociavelmente, tendo limpidez de que cuidar não limitasse a trocar fraudar, alimentar ou dar banho, assim como educar não se restringe a um ensino formalizado em prol de resultados extrínsecos, ou seja, não deve-se perceber o cuidado como somente o corpo e o educar como somente ensinar, desse modo, essas concepções devem ser percebidas de forma múltipla e interligada, afim de abranger as demandas coletivas e individuais das crianças.

Sabe-se que, a primeira etapa da educação básica representa um papel importante na perspectiva de desenvolvimento integral do educando, com uma ênfase que reporta intrinsecamente uma fase de experiências que impactam de modo duradouro nas estruturas cerebrais para as emoções, linguagens, memória, comportamento, 
visual e sensório-motor. É inegável a importância da Educação Infantil sobre o desenvolvimento da primeira infância, e nessa abordagem temos a presença constante do binômio cuidar e educar.

Mas afinal o que é o cuidado para a Educação Infantil? Com base nos estudos realizados por Sayão (2010) o cuidado nessa etapa apresenta uma visão mais ampla e irrestrita da perspectiva reducionista do cuidado como sendo somente relacionado as questões de higiene. Evidentemente, as questões interligadas ao corpo físico, fazem parte integrante do cuidado, mas não somente, o cuidado na Educação Infantil vai além do tabu que o associa a um trabalho "sujo". Por outro lado, ele pode ser compreendido como uma necessidade básica de todo ser humano, que deve considerar integradamente questões do corpo físico, emocionais e individuais, possibilitando descobertas e aprendizagens. Assim sendo, o cuidado representa tanto questões envoltas propriamente a higiene corporal ou alimentação, quanto a uma perspectiva educativa das crianças.

Entretanto, sabe-se que historicamente as considerações da sociedade frente ao ato de cuidar, sempre estiveram atreladas a funções familiares, e a escola resta um aspecto formalizado de educação. Com isso, três questões fazem-se presentes: É possível delimitar o cuidado? Em que medida ele se diferencia e se associa a educação? É possível identificar atividades de cuidado? Essas indagações, nos leva a refletir que "Todas as crianças possuem estas necessidades de cuidado e, se todas têm o direito à educação, qualquer instituição que as atenda deve levá-las em conta ao definir seus objetivos e seu currículo" (CAMPOS, 1994, p.35) no entanto, no cerne das escolas, intrinsecamente das creches, as quais contemplam crianças de 0 a 3 anos e 11 meses, demandando com maior ênfase cuidados elementares, percebe-se uma recusa por parte dos educadores de reconhecerem que o cuidado é um elemento diretamente relacionado a ação educativa,

Não é raro que "as meninas" da Educação Infantil, ou as "tias" mencionadas por Paulo Freire, sejam vistas por seus pares - que atuam em outros segmentos -, pela gestão, pelos responsáveis e pela sociedade em geral, como sujeitos que desempenham funções menores, inferiores, que teoricamente não necessitam de formação 
específica, como por exemplo, dar banho, trocar fralda e brincar. Não é à toa que as discussões expostas anteriormente sobre o binômio educarcuidar estejam sempre presentes e culminem na profissionalidade desse docente. Esses pontos refletem na concepção de identidade e valorização desses profissionais que, muitas vezes, acabam reforçando esse tipo de comportamento em suas ações no cotidiano da escola e nos discursos que proferem sobre a sua realidade. (FERREIRA; GUEDES, 2020, p.10)

Infiro que possivelmente isso ocorre pela falta de limpidez sobre o cuidar de forma ampla, uma vez que na creche, em decorrência da faixa etária atendida, a dissociação entre cuidar e educar, seria propriamente um equívoco, entendendo que cuidar educando e educar cuidando, são princípios essenciais no desenvolvimento infantil.

Neste contexto, é importante evidenciar que o cuidado é uma presença constante nas creches, perpassando questões de acolhimento, afeto, proteção/segurança, alimentação, higiene, limpeza, percepções ligadas ao sono, choro, inquietudes e balbucios, atenção as questões ligadas à saúde básica, como febre, cólicas, diarreias, e a destreza para perceber as questões gerais e essenciais da criança em sua fase de desenvolvimento e a sensibilidade para atender suas demandas individuais. Esses aspectos apontados, permitem refletir que esse ato de cuidar configura-se como parte integrante da educação, demandando por parte do educador saberes específicos, que se relacionam com conhecimentos técnicos por meio de constantes atualizações para compreender as especificidades e demandas das crianças, e juntamente conhecimentos prévios associados a constantes reflexões da ação docente em prol de melhorias.

\subsection{AUXILIARES SOMENTE CUIDAM?}

[...] O que faz a Auxiliar? A Auxiliar faz docência. Todavia esta profissional parece ser responsável por apenas uma parcela das atividades docentes, isso porque, de modo geral, realiza as atividades de cuidado e educação que estão mais relacionadas à dependência e vulnerabilidade das crianças. Como ainda parece persistente a percepção de que o ato de cuidar está relacionado às práticas dirigidas somente ao corpo, as quais, supostamente, não seriam necessários conhecimentos, habilidades e competências específicas para realizá-las, 
é comum a afirmativa de que "a Auxiliar cuida e a professora educa" (PINHEIRO, 2017, p.92)

Os documentos oficiais datados entre 1996 (LDB) a 1998 (RCNEI), já previam que não existe um cuidado que não seja essencialmente educativo, com isso, torna-se curioso perceber que mais de duas décadas depois, a atuação de profissionais especialmente em creches, ainda se expressa com grande negligencia e desvalorização. Neste contexto, tem-se a presença das Auxiliares, pajens, monitoras, atendentes de maternais, berçaristas ou crecheiras, nomenclaturas diversas que visam referenciar as profissionais que atuam majoritariamente em creches e que mantém um contato direto e duradouro com as crianças no cotidiano escolar.

As auxiliares são em tese as profissionais que atuam no auxílio das atividades (pedagógicas e principalmente de cuidados) das crianças junto ao professor titular de sala, como reitera as autoras,

[...] ao falar sobre as diferenciações das tarefas do auxiliar e do professor, considerando o auxiliar como aquele que cuida da higiene, da limpeza, do banho e do auxílio ao professor. O professor tem tarefas que devem ser cumpridas obrigatoriamente como: plano de curso, planejamentos, avaliações entre ou outros. (ANGHINONI; POZZOBON, 2016, p.10)

As atribuições previstas para o cargo de auxiliar, em muitos casos apresenta forte inconsistências na realidade escolar, uma vez que, faz-se ainda muito comum que no cotidiano das creches sejam essas profissionais que supram as demandas de escassez de professores, assumindo salas em seu amplo contexto e sem o devido reconhecimento. A atuação das auxiliares ainda é percebida socialmente em seu aspecto assistencialista, em que limitasse ao "cuidar" de forma a desprestigiar esse ato e as profissionais que atuam na primeira infância, que majoritariamente não tem reconhecimento como pertencentes ao quadro do magistério, e enfrentam as precariedades salariais e do cotidiano do sistema educacional. Com isso, a qualificação exigida, as funções exercidas, o reconhecimento salarial e a identidade profissional tornam-se muito inconsistentes e divergentes, estando diretamente relacionados a deliberações de cada município. 
Neste mesmo contexto, torna-se válido ressaltar que o profissional que atua na Educação Infantil, deve ter em sua base de formação, conhecimentos específicos que propicie o desenvolvimento pleno das crianças envolvidas, como define o RCNEI,

O trabalho direto com crianças pequenas exige que o professor tenha uma competência polivalente. Ser polivalente significa que ao professor cabe trabalhar com conteúdos de naturezas diversas que abrangem desde cuidados básicos essenciais até conhecimentos específicos provenientes das diversas áreas do conhecimento. Este caráter polivalente demanda, por sua vez, uma formação bastante ampla do profissional [...] (RCNEI, 1998, p. 41)

O RCNEI, em acordo com a LDB em seu art. 62 no título $\mathrm{VI}$, aponta que o profissional de educação atuante na primeira infância, deve ter como base para sua ação, uma formação regular e constante que garanta uma performance em prol da educação de qualidade. Visto isto, evidencia-se uma luta das auxiliares (concursadas) em serem reconhecidas como profissionais da educação, desde que atendam às exigências de formação mínima para tal efetivação, uma vez que,

[...] as contradições encontradas na LDB (1996), que não reconhecem a figura do auxiliar, destacando que a titulação mínima para trabalhar com crianças pequenas é a de nível médio, na modalidade Normal, portanto do professor de Educação Infantil. Isso, muitas vezes, gera conflitos em relação ao papel do auxiliar e do professor, produzindo um binômio entre cuidar e educar, reforçando as ideias de trabalho intelectual e manual, de separação entre as atividades voltadas para o corpo e aquelas voltadas para o desenvolvimento mental/intelectual. (ANGHINONI; POZZOBON, 2016, p.09)

Esta discussão da legitimação da luta das auxiliares pelo reconhecimento na carreira docente, percorre as unidades escolares do Município de Carapicuíba, que assim como outros municípios do estado de São Paulo, ainda mantém estas profissionais atuantes nas creches com a diferenciação direta com o Professor de Educação Infantil. A manutenção destes cargos sem respaldo legal, reportasse a uma perspectiva histórica da Educação Infantil, em que especialmente na creche, o trabalho pautado com o cuidar, torna-se diretamente relacionado a um trabalho "sujo", em que os profissionais atuantes não necessitam de conhecimentos científicos 
específicos e muito menos de reconhecimento profissional, como reitera Sayão (2010, p.77)

[...] formação e melhoria dos níveis de escolarização dos/as profissionais fica, muitas vezes, prejudicada pela visão comum de que para "cuidar de crianças", assim como o faziam as escravas, não é preciso formação. Basta gostar de crianças, ter jeito e vocação

Essa herança histórica de um espectro limitado da ação das profissionais que se dedicam a infância, reflete a visão que ainda persiste das Auxiliares como trabalhadoras (maioria do sexo feminino) sem formação e que atuam somente com os cuidados elementares das crianças. Como implicação disso, as auxiliares não têm valorização profissional, o que impacta diretamente na oferta da educação de qualidade, pois desvalorizar os profissionais da educação infantil é juntamente desvalorizar a importância dessa fase para constituição do sujeito/criança como cidadão de direitos e deveres, ao mesmo sentido que, ao valorizar as profissionais que lidam diretamente com a primeira infância, significa perspectivar uma Educação Infantil pública de qualidade. Como reitera Pinheiro,

Quando os docentes estiverem sujeitos às condições adequadas de trabalho e contratação, sendo admitidos como professores e não como Auxiliares, recebendo salários justos pela função que exercem, desfrutando do direito que possuem à formação continuada, conforme o artigo 62 da LDB (BRASIL, 1996), a fim de refletir e ressignificar à docência como profissão a partir do binômio cuidado e educação, é que poderá ser iniciado parte do percurso da longa jornada por um serviço de boa qualidade, não apenas aos professores, mas, consequentemente, às crianças. (PINHEIRO, 2017, p.93-94)

\section{METODOLOGIA}

A abordagem deste estudo caracteriza-se como a princípio uma revisão bibliográfica apoiada em documentos oficiais sobre a educação infantil como a Lei de Diretrizes e Bases (1996) e o Referencial Curricular Nacional para Educação Infantil (1998), juntamente considerou-se alguns autores relevantes sobre a temática como Sayão (2010); Pinheiro (2017); Ferreira e Guedes (2020) e outros. 
Para atender o objetivo da pesquisa, foi realizado um questionário de cunho quantitativo, a fim de produzir dados que desvelassem o perfil educacional das profissionais auxiliares que atuam no município de Carapicuíba (SP). Essa estratégia metodológica foi adotada por permitir gerar dados estatísticos importantes para a caracterização da pesquisa de cunho descritivo, "[...] Para viabilizar essa importante operação da coleta de dado, são utilizados, como principais instrumentos, a observação, a entrevista, o questionário e o formulário [...]" (MANZATO; SANTOS, 2012, p.04).

As auxiliares e pajens foram convidadas a responderem as seguintes questões: Sexo; Nível de escolaridade: Ensino médio, Pedagogia Completo e Pedagogia cursando; Regime de trabalho e Escola de atuação. Após responderem o questionário, os dados foram coletados e tratados pela pesquisadora.

\section{RESULTADOS E DISCUSSÃO}

Com o desígnio de reafirmar os estudos feitos ao decorrer do artigo frente as auxiliares e a busca pelo reconhecimento docente, realizou-se uma análise dos dados levantados com as respostas aferidas por 336 profissionais entre auxiliares e pajens.

Com as respostas tornou-se possível constatar que os sujeitos da pesquisa são todas concursadas em regime Estatuário, e 100\% do sexo feminino, trabalhando na educação infantil creche ou no Atendimento Educacional Especializado em préescolas e ensino fundamental I. As informantes atuam divididas em um total de 34 escolas, 6 (18\%) de ensino fundamental I e 28 (82\%) de Educação Infantil. Ao responderem sobre o nível de escolarização, ficou evidente que a maioria das funcionárias ou concluíram a graduação ou estão em curso, denotando que não são profissionais leigas na área da educação, como pode ser visto no gráfico 1 , em que revela que das 336 informantes, 254 tem graduação em pedagogia completo (75\%), 39 ensino médio/magistério (12\%) e 43 estão com graduação em pedagogia em curso $(13 \%)$. 
Gráfico 1 - Nível de escolarização.

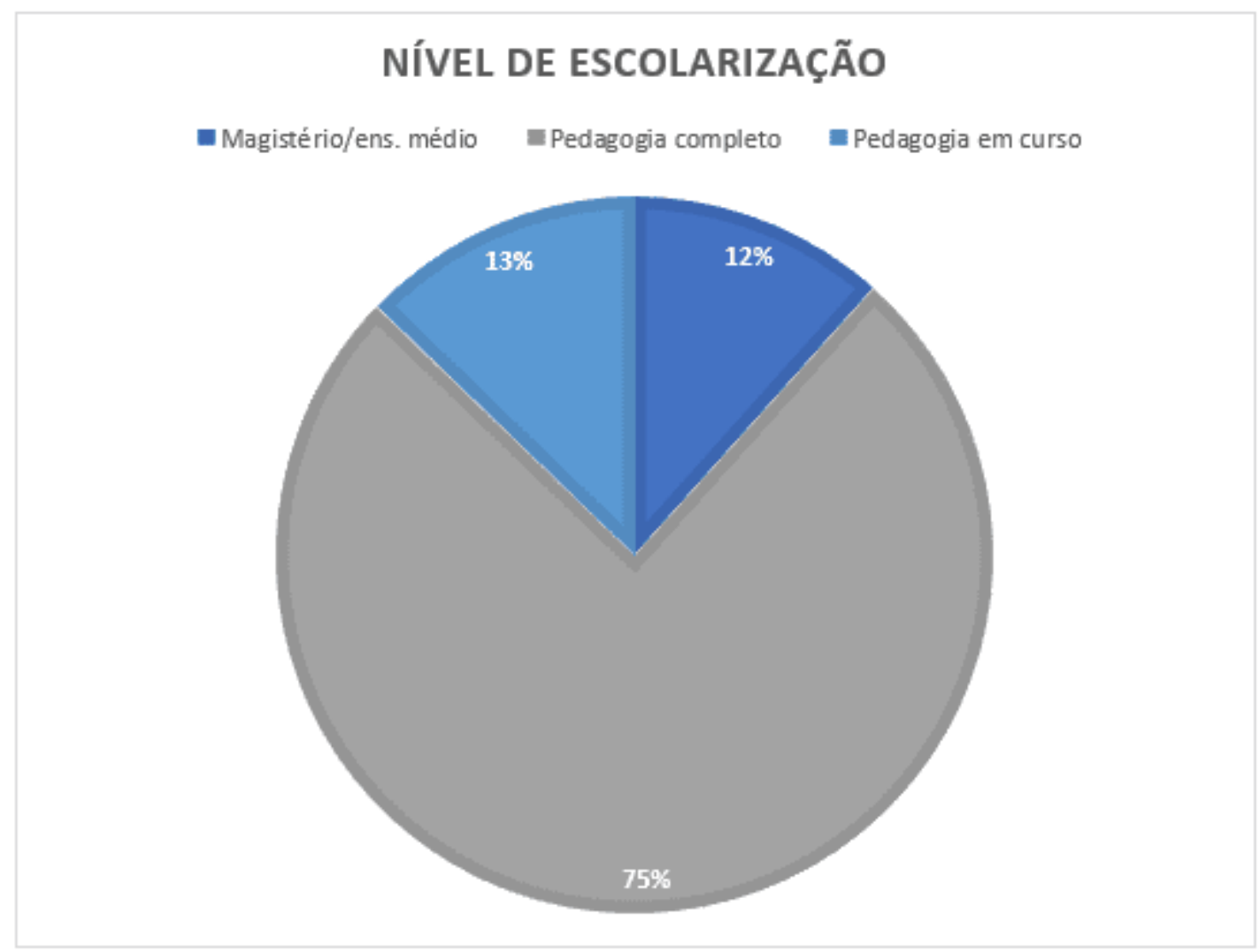

Fonte: Autora (2020)

Esse perfil traçado das auxiliares e pajens no município de Carapicuíba vem ao encontro da insatisfação da categoria pela ausência de reconhecimento profissional, pois uma parcela muito grande dessas trabalhadoras possuem conhecimentos específicos pedagógicos, o que as impedem de diferenciar o papel do auxiliar e do professor, do cuidar e do educar, compreendendo que são concepções indissociáveis e que devem ser consideradas em prol de apaziguar conflitos entre o que é puramente papel do auxiliar e puramente papel do professor, como sugerido em 1998 pelo RCNEl, a gestores e municípios,

[...] deverão criar condições de formação regular de seus profissionais, ampliando-Ihes chances de acesso à carreira como professores de educação infantil, função que passa a lhes ser garantida pela LDB, caso cumpridos os pré-requisitos. Nessa perspectiva, faz-se necessário que estes profissionais, nas instituições de educação infantil, tenham ou venham a ter uma formação inicial sólida e consistente acompanhada de

Disponível em: https://www.nucleodoconhecimento.com.br/educacao/auxiliares-na-educacao 
adequada e permanente atualização em serviço. Assim, o diálogo no interior da categoria tanto quanto os investimentos na carreira e formação do profissional pelas redes de ensino é hoje um desafio presente, com vista à profissionalização do docente de educação infantil. (RCNEI, 1998, p.39-41)

No próprio RCNEI (1998), a nomenclatura utilizada para nomear o profissional atuante com a educação das crianças é Professor de Educação Infantil, sem distinção com o auxiliar. Nesse sentido, evidencia-se a importância do reconhecimento das auxiliares formadas com também professoras, uma vez que, a valorização da profissão docente, implica diretamente na valorização das crianças como sujeitos globais que necessitam de profissionais capacitados com conhecimentos específicos para garantir seu pleno desenvolvimento.

\section{CONSIDERAÇÕES FINAIS}

Com base na pesquisa realizada e nas respostas aferidas ao questionário, torna-se possível pleitear que a problemática inicial deste artigo, que foi verificar se a formação educacional das auxiliares no município de Carapicuíba estava de acordo com as exigências de leis para o cargo de professor, foi respondida, desvelando que a maior parte destas profissionais tem graduação completa ou no mínimo está cursando, com isso, tornou-se evidente que o desejo pelo reconhecimento como professoras de Educação Infantil, apresenta um respaldo legal e de identidade profissional.

Contudo, esta pesquisa não tem a pretensão de dualizar a função do professor e do auxiliar, mas pretende desvelar uma reflexão sobre o papel docente na Educação Infantil, e como a distinção histórica entre cuidar e educar ainda reflete diretamente na identidade dos profissionais que se dedicam a primeira infância. Portanto, o desejo das auxiliares em terem o papel docente oficialmente reconhecido, perpassa uma luta histórica pelo rompimento do caráter assistencialista das creches e a ruptura do dualismo entre cuidar e educar, efetivando uma luta profissional pela infância e pela educação infantil pública de qualidade. 


\section{REFERÊNCIAS}

ANGHINONI, Márcia Hende Pereira; POZZOBON, Marta Cristina Cezar. AS ATRIBUIÇÕES DO AUXILIAR DE EDUCAÇÃO INFANTIL NA PERSPECTIVA DOS PROFESSORES DE UMA EMEI DE ARROIO GRANDE. S.I. p. 14, 2016. Disponível em:https://dspace.unipampa.edu.br/bitstream/riu/2318/1/M\%C3\%A1rciaHendePereir aAnghinoni2017.pdf . Acesso em: 20 jul. 2020

BRASIL. Diretrizes Curriculares Nacionais para a educação Infantil. Resolução n`5, de 17 de dezembro de 2009.

BRASIL. Lei de Diretrizes e Bases da Educação Nacional. Lei número 9394, 20 de dezembro de 1996.

BRASIL. Ministério da Educação e do Desporto. Secretaria de Educação Fundamental. Referencial Curricular Nacional para a Educação Infantil /Ministério da Educação e do Desporto, Secretaria de Educação Fundamental. Vol.3. Brasília: MECISEF, 1998.

FERREIRA, Michelle Dantas; GUEDES, Adrianne Ogêda. Formação sem fôrma: a singularidade do processo de ser professor da Educação Infantil. Educação, Porto Alegre, v. 43, n. 1, p. 1-12, jan.-abr. 2020 | e-29757. Disponível em: https://revistaseletronicas.pucrs.br/ojs/index.php/faced/article/view/29757/19636.

Acesso em: 24 jul. 2020.

MANZATO, Antonio José; SANTOS, Adriana Barbosa. A ELABORAÇÃo DE QUESTIONÁRIOS NA PESQUISA QUANTITATIVA. S.I. UFSC p. 17, 2012. Disponível em: http://www.inf.ufsc.br/ vera.carmo/Ensino_2012_1/ELABORACAO_QUESTIONARIO S_PESQUISA_QUANTITATIVA.pdf. Acesso em: 24 de jul. 2020

NASCIMENTO, Maria Letícia Barros Pedroso. A CRECHE NA EDUCAÇÃo INFANTIL: ENTRE O OFícIO E O DIREITO. Estud. sociol., Araraquara, v.15, n.29, p.555-566, 2010. 
PINHEIRO, Maria Nerice dos Santos. "NÃO! A AUXILIAR NÃO É A PROFESSORA": O PAPEL DAS AUXILIARES DA EDUCAÇÃO INFANTIL NO CONTEXTO DE CRECHE NO MUNICÍPIO DE FORTALEZA. - 2017. 340 f. : il. color. Dissertação (mestrado) - Universidade Federal do Ceará, Faculdade de Educação, Programa de Pós-Graduação em Educação, Fortaleza, 2017. Disponível em: http://www.repositorio.ufc.br/bitstream/riufc/29900/1/2017_dis_mnspinheiro.pdf. Acesso em 24 jul. 2020

SAYÃO, Déborah Thomé. Não basta ser mulher... não basta gostar de crianças... "Cuidado/educação" como princípio indissociável na Educação Infantil. Educação, Santa Maria, v. 35, n. 1, p. 69-84, jan./abr. 2010 Disponível em: https://periodicos.ufsm.br/reveducacao/article/view/1604/899. Acesso em: 06 jun. 2020

\section{APÊNDICE - REFERÊNCIA DE NOTA DE RODAPÉ}

2. Carapicuíba localiza-se no estado de São Paulo, a cerca de $26 \mathrm{Km}$ da capital.

Enviado: Julho, 2020.

Aprovado: Dezembro, 2020. 